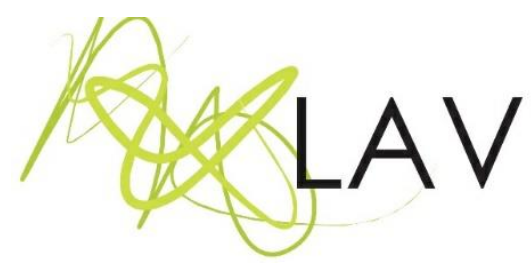

\title{
Encontros com o cinema de animação e com crianças na produção de filmes sobre direitos humanos
}

Encounters with animation cinema and kids in the production of films about human rights

Constantina Xavier Filha ${ }^{i}$

Universidade Federal do Mato Grosso do Sul

\section{Resumo}

Este artigo faz parte de uma pesquisa mais ampla realizada no estágio de pós-doutorado na Pós-Graduação em Educação da Unirio (2019-2020). Tem por propósito descrever o conceito de encontros com o cinema de Bergala (2008), traçar parte de minha trajetória como pesquisadora até os encontros com as crianças, nas experiências de produção de filmes de animação, em projeto de pesquisa e de extensão. Os filmes produzidos, doze, ao total, com estudantes do $3^{\circ}$ ao $5^{\circ}$ ano do Ensino Fundamental, têm como temasargumentos: infâncias; gênero; direitos humanos; violência contra crianças; fazer cinema; corpo/autocuidado/autoproteção. Todos os temas têm relação direta com a defesa dos direitos humanos das crianças. Ao discutir sobre eles, recorre-se a alguns dos filmes produzidos, assim como a informações de pesquisas realizadas com as crianças, para saber como elas pensam sobre este e outros temas, como dignidade humana, direitos e deveres e redes de proteção.

Palavras-chave: Encontros com o cinema, cinema de animação, direitos humanos.

\begin{abstract}
The article is part of a broader research carried out in the postdoctoral internship in the Graduate Program in Education at Unirio (2019-2020). Its purpose is to describe the concept of encounters with cinema by Bergala (2008), to trace part of my trajectory as a researcher until the encounters with children, in the experiences of producing animated films, in a research and extension project. The films produced, twelve in total, made with students from the 3rd to the 5th year of elementary school, have as their topicarguments: childhood; genre; human rights; violence against children; making films; body/self-care/self-protection. All topics are directly related to the defense of children's human rights. When discussing them, some of the films produced are recalled, as well as information from research conducted with children to learn how they think about these and other topics, such as human dignity, rights and duties, and safety nets.
\end{abstract}

Keywords: Encounters with the cinema, animation cinema, human 


\section{PARA INICIAR NOSSO ENCONTRO...}

Os encontros com o cinema e com as crianças para fazer filmes serão aqui descritos, narrados e problematizados. Dois temas serão utilizados como conceitoschave: encontros com o cinema e direitos humanos. Na primeira etapa do texto, pretendo descrever parte de minha trajetória com relação ao audiovisual, meus encontros com a televisão e, depois, com o cinema, até chegar ao grande encontro com o cinema de animação, que se tornou o grande preferido e amado dentre outras linguagens e formas de fazer cinema. Não que eu não ame os 'outros' tipos de cinema. Aprecio-os, até porque acredito que podemos apreciar muitas coisas e amar pessoas ao mesmo tempo, mas confesso a minha predileção pelos filmes e pelo cinema de animação.

Descreverei, posteriormente, como cheguei até as crianças nas escolas, encontro maravilhoso e apaixonante, para produzir filmes de animação juntamente a elas e como descobri a surpreendente possibilidade de tematizar direitos humanos. Momento mágico e arrebatador em minha vida. Ouso afirmar que sou alguém diferente depois desses encontros. Concomitantemente, no decorrer do período, venho a cada dia mais me encontrando e me constituindo como estudiosa e academicamente comprometida com os estudos de gênero, direitos humanos, sexualidades, estudos feministas e feminismos. Posso, então, dizer que, à medida que me torno cinéfila, também me torno mais defensora dos direitos humanos, sobretudo das crianças e das mulheres, e mais feminista, ou tentando ser, aprendendo cada vez mais nos encontros e desencontros desses campos teórico-práticos em minha vida pessoal e profissional, aspectos a cada dia mais desafiadores no país, nas épocas atuais em que nos encontramos!

Os filmes foram produzidos em projetos de pesquisa e extensão no âmbito da Faculdade de Educação da Universidade Federal de Mato Grosso do Sul, campus de Campo Grande, com apoio da Pró-Reitoria de Extensão. Iniciamos ${ }^{1}$ os projetos no ano de 2010 e até o momento produzimos 12 filmes - refiro-me, aqui, às crianças e equipe, que contou com acadêmicas e acadêmicos do curso de Pedagogia, aos quais agradeço imensamente, além de muitas outras pessoas que colaboraram durante todo esse processo, aos/as integrantes do Grupo de Estudos e Pesquisas em Sexualidades, Educação e Gênero (Gepsex) que tomaram parte, sem esquecer os/as integrantes das escolas públicas municipais em que, juntos/as, realizamos os projetos, especialmente professoras e professores responsáveis pelas turmas.

\footnotetext{
${ }^{1} \mathrm{Em}$ alguns momentos, utilizo a primeira pessoa do plural, porque não consigo falar em meu nome próprio sobre ações de projetos tão plurais e repletos de coletivos, de pessoas diversas, durante toda a minha e a nossa trajetória.
}

Revista Digital do LAV - Santa Maria - vol. 13, n. 2, p. 291 - 311 - mai./ago. 2020 ISSN 1983 - 7348 http://dx.doi.org/10.5902/1983734844248 
As temáticas se referem às seguintes áreas de estudo e de pesquisa: gênero, sexualidades, direitos humanos, violência contra crianças, corpo, autocuidado/ autoproteção. O tema 'guarda-chuva' dos filmes é direitos humanos, razão pela qual passarei a discutir a partir de alguns dos filmes produzidos, apesar de afirmar que todos tratam desse tema de forma transversal. Também serão aqui tratadas informações de pesquisas realizadas com as mesmas crianças que produziram os filmes, por constituírem parte do projeto de pesquisa e intervenção na extensão universitária para a produção dos filmes.

\section{Encontros com o cinema e com as crianças}

"Se o encontro com o cinema como arte não ocorrer na escola, há muitas crianças para as quais ele corre o risco de não ocorrer em lugar nenhum".

(BERGALA, 2008, p. 33)

O conceito encontros com o cinema, utilizado neste artigo, é inspirado em Bergala (2008). O autor nos convida a pensar o cinema como alteridade por nos permitir, ao assistir a filmes, tornar-nos outra pessoa. O cinema como arte, para ele, não se ensina, mas se encontra, se experimenta. O autor nos instiga a questionar o cinema na escola como arte: "para permanecer arte, deve permanecer um fermento de anarquia, de escândalo, de desordem. A arte é, por definição, um elemento perturbador dentro da instituição. Ela não pode ser concebida pelo aluno sem a experiência do 'fazer' $[\ldots]$ " (BERGALA, 2008, p. 30). Enfatiza, ainda, o encontro com o cinema na escola, bem como as "emoções da própria criação" (ibid., p. 35). Segundo ele, a "escola representa hoje, para a maioria das crianças, o único lugar onde esse encontro com a arte pode se dar" (ibid., p. 32). E vai além, ao afirmar que "se o encontro com o cinema como arte não ocorrer na escola, há muitas crianças para as quais ele corre o risco de não ocorrer em lugar nenhum" (ibid., p. 33), citação transcrita na epígrafe desta seção.

Para Bergala (2008), a escola pode ser um espaço rico de possibilidades onde os encontros com o cinema podem ocorrer. Ele é enfático ao dizer que a escola é "o único lugar em que esse encontro com a arte pode se dar" (BERGALA, 2008, p. 32) para muitas crianças, como dito anteriormente. Esse encontro seria algo 'perturbador', que produz questionamentos e desordem na instituição. O papel da escola, ${ }^{2}$ da professora ou

\footnotetext{
2 A Lei n 13.006 de 2014 assegura, no $\S 8^{\circ}$ que a "exibição de filmes de produção nacional constituirá componente curricular complementar integrado à proposta pedagógica da escola, sendo a sua exibição obrigatória por, no mínimo, 2 (duas) horas mensais". A lei alterou a LDB, assegurando que o cinema deve estar presente nas escolas por no mínimo duas horas, não somente como imposição, mas como possibilidade pedagógica e artística de trazer o cinema como arte para o encontro de crianças e adolescentes.
} 
professor é de possibilidades e de fomento para que a arte promova mudanças significativas na instituição e na vida das pessoas. Essa promoção de encontro com as várias possibilidades de interagir com a magia da arte é transformadora: incomoda, desestabiliza, comove, promove identificação e rejeição; instiga outras formas de ver, de sentir, de estar no mundo, bem como questionamentos e ainda produz outros olhares e novas formas de ser.

Venho, há algum tempo, pensando no cinema, em especial no de animação, embora isso se aplique a qualquer de suas modalidades e linguagens, como instrumento instigante e potente de produção de pensamento. Sabemos que pensar não é algo inato na vida dos sujeitos, pois não nascemos pensando, mas aprendemos a pensar. Gallo (2012) assegura que o pensamento é "produzido, fabricado, inventado" (GALLO, 2012, p. 108). Aprendemos a pensar, conforme o autor, inventando nossas próprias maneiras de nos relacionar com os signos do pensamento. A partir dos conceitos deleuzianos, Gallo escreve que o "pensar é experimentar o incômodo do desconhecido, do ainda não pensado e construir algo que nos possibilite enfrentar o problema que nos fez pensar" (2012, p. 72).

Venho experimentando o incômodo, a delícia do exercício e da experiência do pensamento com crianças ao ver/fruir filmes e ao produzir animações com elas. Nessas experiências, promovi encontros com o cinema como arte e vivenciei a arte de brincar de fazer cinema com as crianças. Muitos privilégios, alegrias, (in)cômodos do (des)conhecido, encontros e desencontros.

O meu encontro, antes de viver a experiência com as crianças, aconteceu como o de muitas pessoas da minha geração, a partir da televisão, ao visualizar filmes ou desenhos animados. Eu era muito mais ligada à televisão do que ao cinema, até porque não havia cinema na pequena cidade do interior do Mato Grosso do Sul onde eu morava, em Nioaque. Na minha infância, adorava assistir, na televisão, aos episódios do Sítio do Picapau Amarelo, obra original de Monteiro Lobato, e ver as peripécias da Emília e da Cuca, minhas personagens preferidas. Cheguei a sonhar em ser atriz e brincava de encenar o papel da Emília, a boneca de pano que era Marquesa de Rabicó e Condessa de Três Estrelinhas. Também assistia às séries que se passavam no final da década de 70 e começo da década de 1980: Casal 20, Mulher Maravilha e Ilha da Fantasia. Assistia aos filmes da Sessão da tarde, na Rede Globo. Lembro-me dos filmes do Roberto Carlos e do Elvis Presley, de quem sou fã até hoje. De desenho animado, lembro-me pouco, mas sem muito entusiasmo: Tom e Jerry e Pantera cor de rosa. O que amava eram os programas de auditório: Cassino do Chacrinha, aos sábados à tarde, e o Show de 
Calouros, de Sílvio Santos, no domingo à noite. Mais tarde, assistia aos programas Viva à noite, de Gugu Liberato, e a Perdidos na noite, de Faustão. Nessa época, já era adolescente. Como esses programas passavam tarde da noite e minha mãe já tinha ido dormir, tinha que fazer uma cabaninha com uma colcha que deveria me cobrir, e também a televisão, para reduzir a luminosidade e, principalmente, o barulho para não a acordar. Isso tudo em um calor escaldante, mesmo à noite, quando a televisão tinha sinal da torre de transmissão que ficava em uma cidade próxima daquela em que eu vivia. A qualquer sinal de chuva no céu, caía o sinal e não se via nada além de um chuviscado desesperador que poderia durar vários dias.

Não lembro, na escola, de algum dia ter visto filmes de curta ou longa-metragem na minha infância, nem mesmo na adolescência. Tenho poucas lembranças do tempo da escola, apesar de sempre ter sido uma aluna aplicada e de ter nutrido verdadeira adoração pelo espaço e pela cultura escolar.

A lembrança que tenho de ter ido ao cinema é a de quando fui a Brasília para uma consulta médica, por ter tido um problema de saúde no início da adolescência. Assisti ao filme de ficção científica ET: o extraterrestre, produzido e dirigido por Steven Spielberg. Eu tinha por volta de 12 anos de idade. Fiquei perplexa e estarrecida com os efeitos especiais e pelo roteiro do filme. O voo de Elliot, em sua bicicleta, carregando o ET, passando em frente à lua, ficou gravada em minha mente como uma das imagens mais lindas do cinema. Depois desse encontro, outros vieram mais tarde, já na idade adulta, quando me mudei para Campo Grande, capital do Mato Grosso do Sul, mas ainda sem a ampliação do repertório cinematográfico para conhecer o cinema com linguagens que não as dos filmes comerciais. Minha família não tinha o hábito de ir ao cinema. Logo que comecei a fazer a faculdade, fui morar sozinha e passei a me sustentar. Daí ir ao cinema era um luxo do qual não podia usufruir.

Meus encontros com o cinema considerado arte e com o cinema de animação ocorreram em São Paulo, muito tempo depois de tudo isso que venho narrando, durante o doutorado em educação, na Faculdade de Educação da USP. Nessa época, passei a frequentar cinemas de arte e a participar de inúmeros festivais de todos os gêneros, locais que me propiciaram os 'encontros' com o cinema e se tornaram espaços formadores culturais durante meus estudos na pós-graduação. Dentre tantos e maravilhosos festivais, um deles, que tanto me sensibilizou a ponto de mudar minha vida, foi o Anima Mundi - Festival Internacional de Animação do Brasil. ${ }^{3}$ Posso dizer que

\footnotetext{
${ }^{3}$ Maior festival de animação do país. É a principal plataforma de promoção de novas linguagens e do setor de animação brasileira desde 1993. Referência na revelação de novos talentos da animação brasileira e no desenvolvimento do mercado cinematográfico e televisivo do país na área de animação. <https://www.facebook.com/pg/festivalanimamundi/about/?ref=page_internal>. Acesso em: 20 abr. 2020.
} 
sou alguém antes e alguém depois desse festival. Foi com ele que tive 'o encontro' com a arte do cinema de animação. Foi por ele que depois pude ter os 'encontros' com as crianças e, posteriormente, os 'encontros' da arte de fazer cinema com as elas nas escolas. Passei a ser uma amante da sétima arte e uma apaixonada pelo cinema de animação.

O primeiro ano em que participei desse festival foi o de 2001 e passei a frequentá-lo, quase que anualmente, até o ano passado. Participo vorazmente, assistindo a quase todas as sessões de filmes de curta e longa-metragem. No começo, participava do Espaço Aberto nas oficinas de desenho animado, massinha, pixilacion ${ }^{4} \ldots$; prestigiava os 'Papos Animados' com os/as diretores/as e produtores/as dos filmes, falando sobre seus processos criativos e de produção dos filmes; sobre os lançamentos dos longasmetragens; sobre as seções dos curtas infantis. Também passei a participar de atividades extra-festival, com cursos e workshops. No festival, deparei-me com uma sessão que me encantou e me tornou cativa - Futuro Animador -, que exibe filmes feitos por crianças, especialmente em escolas. Não perdia nenhuma dessas sessões. Começou a nascer em mim o desejo de fazer cinema de animação, mas ainda não sabia bem como, nem onde realizá-lo, ainda mais para mim, com formação em Pedagogia e com conhecimentos distantes da área da arte e do cinema. Esse desejo, porém, ia aumentando à medida que frequentava, anualmente, o festival. Comecei a fazer alguns cursos na área de arte e alguns cursos livres na área de cinema. À época, os cursos de cinema de animação não eram muito comuns no Brasil, em especial no interior do país, onde morava. No entanto, nada esmorecia meu intuito. Nas minhas andanças pelo festival, conheci o projeto Anima Escola. ${ }^{5}$ Trata-se de um projeto nascido no âmbito do festival, que desenvolve ações educativas em escolas, ensinando técnicas do cinema de animação para docentes e alunos/as. Vi, nas ações do projeto, a possibilidade de efetivar e tornar real o meu sonho.

No ano de 2008, coordenei, no âmbito da Universidade Federal de Mato Grosso do Sul, da qual sou professora na Faculdade de Educação, o projeto de extensão "Educação para a Sexualidade, Equidade de Gênero e Diversidade Sexual: práticas e materiais educativos", com o apoio da Secretaria de Educação Continuada, Alfabetização e Diversidade (Secad/MEC). Esse projeto, além dos momentos sistematizados de formação continuada - com a discussão teórico-metodológica sobre os temas

\footnotetext{
4 Pixilation é uma técnica de animação stop motion na qual seres vivos são utilizados e captados quadro a quadro (como fotos), criando uma sequência de animação.

${ }^{5}$ O Anima Escola é um projeto, criado pela equipe do Anima Mundi, que leva a linguagem da animação para escolas. Disponível em: <https://www.facebook.com/pg/animaescolaoficial/about/?ref=page_internal>. Acesso em: 20 abr. 2020.
}

Revista Digital do LAV - Santa Maria - vol. 13, n. 2, p. 291 - 311 - mai./ago. 2020 ISSN 1983 - 7348 http://dx.doi.org/10.5902/1983734844248 
sexualidades, gênero e diversidade sexual -, tinha por objetivo produzir materiais educativos. Estabeleci parceria com o Anima Escola para o desenvolvimento de oficinas de produção de filmes de animação com dois grupos de professoras e cursistas de nosso projeto. Essa foi minha primeira experiência em produção coletiva de dois curtasmetragens de animação com a turma das professoras, em parceria com os/as monitores do Anima Escola. Esses filmes compuseram o Kit de Materiais Educativos de Educação para a Sexualidade, para a Equidade de Gênero e para a Diversidade Sexual, sob minha coordenação (XAVIER FILHA, 2009a).

A experiência foi importante para observar o processo pedagógico da produção do cinema de animação e reacender o desejo de continuar a viver esse processo. Percebi, porém, que algo faltava. O desejo era viver essa experiência com as crianças. Não sabia, ao certo, como efetivar esse objetivo, porque atuava profissionalmente na universidade, com a formação docente em curso de Pedagogia, e estava diretamente ligada a um grupo de pessoas adultas. Como chegar a um grupo de crianças? Como realizar um projeto com as crianças em escola? Como fazer filmes com crianças? Estava segura para produzir com as crianças? Eram muitos questionamentos e inúmeros desafios, muitos deles sem resposta ou perspectiva para a sua realização, mas eu não desanimava.

No ano de 2009, com um projeto de pesquisa apoiado pelo CNPq, denominado 'Gênero e sexualidade em livros infantis: análises e produção de material educativo para/com crianças' (2008-2012), que tinha por propósito coletar e analisar livros infantis sobre as temáticas de gênero e sexualidade e, em um segundo momento, levar os livros até as crianças, tive a possibilidade de me encontrar com elas, ainda não para necessariamente fazer filmes, mas para discutir com elas sobre os livros infantis. Outra paixão!

Em 2010, no âmbito dessa pesquisa e de um projeto de extensão, iniciei a trajetória com crianças, primeiro, para discutir sobre os livros e, depois, para, a partir deles, fazer filmes de animação. Eis que o tão sonhado encontro com as crianças aconteceu. A escola escolhida foi uma instituição pública, situada na periferia de Campo Grande/MS, nas proximidades da universidade. Optei por uma escola em que pudesse contar com uma pessoa que integrasse o grupo de estudos que coordeno, o Gepsex no seu quadro de professora. O objetivo era que houvesse alguém que pudesse abrir caminhos na instituição e que me representasse na escola quando não estivesse presente. Essa estratégia facilitou o nosso trânsito na escola e fomos muito bem recebidas pela diretora, que acolheu o projeto e nos autorizou a desenvolver as ações em duas salas do quinto ano do ensino fundamental, segundo ela, as duas salas "mais difíceis da escola e que precisavam de educação sexual". Aceitamos prontamente o 
desafio e começamos os trabalhos, programados uma vez por semana durante um período de quatro horas por dia em cada uma das salas, em um período de cinco meses. A ideia, nesse primeiro projeto, foi a de levar os livros infantis coletados na pesquisa para servir de discussão sobre temáticas de gênero e sexualidade e, depois, pensarmos na produção de algum material didático. Pensávamos, no início, em material escrito, mas, ao longo do projeto, vimos que o audiovisual era algo que mais prendia a atenção e o desejo do grupo, daí partirmos para a ideia da produção do filme de animação com as crianças. Meu sonho, de cerca de nove anos antes desse encontro, final e felizmente se efetivava com as crianças! Como já disse e volto a afirmar, nunca fui a mesma pessoa depois desse encontro, principalmente depois de fazer filme com as crianças.

O projeto contava com encontros semanais com cada uma das turmas, além de um seminário final de síntese, realizado na universidade, no intuito de socializar as atividades desenvolvidas e exibir o filme de animação produzido coletivamente com as duas turmas. Durante todos esses anos de projetos, experimentamos, eu e equipe, várias metodologias, ações, atividades com as crianças no processo de pensar junto e produzir filmes de animação. Em 2013-2014, fiz uma pesquisa de pós-doutorado na Unicamp, com supervisão do prof. dr. Sílvio Gallo. Na ocasião, pensei sobre o processo das experiências vividas nos projetos. A partir desse estudo, reorganizei as etapas teórico-metodológicas dos projetos, que passaram a se constituir em três, interdependentes, aos quais passarei a descrever a seguir.

Denominei a primeira etapa do trabalho desenvolvido com as crianças de brincar de pensar em si e no mundo, atividade diagnóstica para conhecer o que as crianças sabiam sobre o tema escolhido. Para cada ano, levamos um tema diferente para ser desenvolvido em cada projeto: gênero, direitos humanos, corpo... depois disso tudo, produzíamos/trabalhávamos, coletivamente, até o produto final, o filme de animação. Várias metodologias de pesquisa foram desenvolvidas juntamente às crianças, seja a roda de conversa, seja a elaboração de pequenos textos e desenhos, a produção de pequenas histórias individuais ou coletivas. Nessa etapa, era importante destacar as falas e saberes das crianças. Outro momento vivenciado nos projetos foi a produção coletiva do filme de animação, intitulada de fazer cinema brincando. As crianças participaram de todo o processo de pré-produção, produção e planejamento da pós-produção, até a sugestão final para a edição dos filmes. A última etapa foi a de ver e pensar o filme, momento de socializar o filme produzido coletivamente entre adultos e crianças. As crianças falaram sobre o processo de produção do filme na universidade em uma mesaredonda e também quando o exibimos na escola para as/os outras/os alunas/os e familiares. Outros questionamentos foram produzidos a partir daí. Tais encontros 
constituíram momentos de fruição, acolhimento, partilha de novos questionamentos, de ver a obra pronta, e também de prospectar novos sonhos, novas ideias, novas formas de produzir com e para as crianças.

É importante frisar, nesse processo, que as crianças aprendem muitas atitudes e habilidades com o trabalho em grupo, como respeito pelas ideias das outras pessoas, enriquecimento da oralidade, da autonomia, da autoconfiança, do sentimento de cidadania e de pertencimento como ser que tem dignidade e exige seus direitos, e nós, pessoas adultas, também. Todas essas questões, além das habilidades de aprender a fazer um filme e perceber os elementos de produção da linguagem cinematográfica de forma respeitosa, trabalhosa, laboriosa, mas lúdica, divertida, leve, colaboradora, sem competitividade.

Durante toda a trajetória, produzimos 12 filmes que se encontram nas páginas das redes sociais do projeto (www.youtube.com/brincardefazercinema). Muitos deles já percorreram festivais, ganharam prêmios, dentro e fora do país. A seguir, uma síntese dos filmes na ordem cronológica das produções:

- Jéssica e Júnior no mundo das cores (3 min., 2010) - história de uma menina que se transforma em cor-de-rosa de tanto viver imersa em um mundo rosa. O mesmo ocorre com o menino que se torna azul. Ambos passam a questionar essa transformação. Filme baseado no livro $A$ menina e o menino que brincavam de ser, de Tina Xavier (2009b).

- Ser criança em Campo Grande: um documentário animado (6 min., 2011) história de uma menina e um menino que narram seu dia vivido em Campo Grande. Descrevem o que mais gostam de fazer na cidade, imaginando-a governada por crianças super-heroínas, com chuva de doces e balas, transformada em docelândia, sorvetelândia e guaranalândia.

- A Princesa Pantaneira (9 min., 2012) - Camuela é uma menina que recebeu dos bichos do seu reino o apelido de Princesa Pantaneira. Ela é corajosa, valente, destemida, desbravadora, doma cavalo bravo e salva príncipes e princesas.

- Queityléia em perigos reais (9 min., 2012) - história de uma menina que, em sonho, faz tudo o que sempre quis dentro de casa, colocando-se em situações de perigo e de vulnerabilidade.

- Direitos das crianças: uma aventura intergaláctica (9 min., 2013) - amizade de duas crianças terráqueas, Lila e Luiz, residentes em Campo Grande, com crianças ETs, Etvaldo e Etnilda, habitantes do Planeta Timbum. Lila e Luiz convidam-nas a passear no planeta Terra. Aqui chegando, conhecem a realidade de outras crianças terráqueas: as que são tratadas com cuidado, alimentação e proteção, e as que têm seus direitos violados.

- João e Maria: dos contos à realidade (9 min., 2013) - versão contemporânea do conto de fadas do mesmo nome. João e Maria são irmãos e foram vendidos por seus pais a um 'casal mau', que morava em uma casa de doces. Lá deveriam realizar trabalhos forçados e descobriram que muitas outras crianças eram escravizadas pelo mesmo casal. 
- Cantando os direitos das crianças (10 min., 2016) - o roteiro foi construído a partir de dois raps escritos por uma das alunas do grupo. O filme mostra a atuação de duas MCs de rap em uma competição, em show de calouras/os. A temática central é a violência contra crianças e direitos humanos.

- Eu protejo o meu corpo (8 min., 2017) - narra os cuidados e formas de proteção que as crianças devem assumir para se proteger e também para buscar ajuda em situações de vulnerabilidade. Baseou-se no livro Do meu corpo eu cuido e protejo, de minha autoria (2014) e ilustrações de Lorena Martins.

- Mariquinha no mundo da imaginação (10 min., 2018) - inspirado livremente nas obras do poeta Manoel de Barros. Conta a história de uma menina que descobre que o seu 'quintal é maior do que o mundo'; explora a natureza, brinca com seu amigo Nardo e vive experiências em seu mundo imaginário.

- Princesa Pantaneira YouTuber (5 min., 2018) - é protagonizado pela Princesa Pantaneira, que agora é uma youtuber. Ela apresenta um programa de um canal da Internet e responde a perguntas de suas/seus seguidoras/es. A pergunta-chave do roteiro do filme é sobre como as crianças podem fazer cinema de animação.

- Princesa Pantaneira responde: cinema (6 min., 2018) - A youtuber Princesa Pantaneira responderá a uma pergunta enviada ao seu canal sobre a história do cinema no mundo e no Brasil.

- Brincar de fazer cinema com crianças (8 min., 2018) - é protagonizado pela Princesa Pantaneira, que agora é uma youtuber. Ela apresenta um programa de um canal da internet e responde a perguntas de suas/seus seguidoras/es. A pergunta-chave do roteiro do filme é sobre como as crianças podem fazer cinema de animação.

Os filmes podem ser acessados livremente tanto para serem vistos por outras crianças, quanto para serem utilizados como instrumentos de discussão com pessoas adultas, por professores e professoras, para alunos/as, como instrumentos pedagógicos nas instituições educativas. Vejo que os materiais, como os que produzimos, podem constituir poderosos artefatos culturais se forem explorados para discutir e debater em sala de aula. Não porque os ache 'perfeitos', longe disso; exatamente pela imperfeição é que podem ser alvo de discussão, para pensar, a partir deles e de seus conteúdos, das personagens, do protagonismo das crianças. Aliás, considero que tudo o que há na cultura, todo e qualquer material, qualquer artefato cultural, desde que seja da compreensão cognitiva e do interesse da criança, pode ser alvo de debate na escola. Esses nossos filmes podem ser um desses instrumentos/recursos pedagógicos, inclusive para acender a chama de produzir outros vídeos e filmes com as crianças, de produzir outros materiais e novos pensamentos, novas ideias, novas personagens, novas músicas, novas expressões artísticas, novas formas de arte como estranhamento, novas formas de pensar...

\section{Pensar sobre direitos humanos nos filmes}


O cinema não é o lugar de coisas belas, apenas, mas também do feio, do insuportável, do estranhamento, do perturbador. Se essa equivalência entre o cinema e as 'coisas belas' se mantém, estamos fossilizando e destruindo a potência disruptiva e inventiva dessa arte (FRESQUET e MIGLIORIN, 2015, p. 6).

O cinema precisa abranger o belo, o feio, o perturbador, o acolhedor, o insuportável, o estranhamento, conforme Fresquet e Migliorin (2015). Não vejo uma visão binária e moral nos temas a serem tratados e pensados na visualização, na fruição, nem mesmo na produção de filmes para e com crianças. Essa temática, por si só, daria um artigo, devido à sua necessidade de discussão, embora sem consenso, algo que não será possível desenvolver no presente artigo. Assim mesmo, quero trazer alguns desses aspectos para pensar no processo vivido com as crianças como coautoras de filmes que falam de temáticas consideradas, por muitos, 'perturbadoras', como as que envolvem violação de direitos de crianças. Em uma das escolas em que realizamos o projeto sobre violência contra crianças e direitos humanos, uma professora de outra turma da escola, ao querer saber do conteúdo de que iríamos tratar no projeto, disse-me que as crianças do quinto ano, as com que à época trabalhávamos, não tinham maturidade e idade para discutir sobre esses temas. No entanto, a afirmação da professora era constantemente contestada em todos os nossos encontros com as crianças, quando começávamos as discussões com a turma. Em um primeiro momento, as crianças se sentiram desconfortáveis e sem saber o que dizer. Parecia que não estavam se sentindo à vontade ou desconfiadas se poderiam de fato falar o que queriam e o que sentiam. Aos poucos, foram se soltando e se sentindo mais seguras para falar, ainda rindo dos/as colegas, não respeitando empaticamente a dor do/a outro/a; aos poucos, fomos construindo um espaço de acolhida para ouvi-las e elas, cada vez, mais queriam falar, dialogar, perguntar, dizer o que sabiam, sobre o que haviam visto, sobre o que tinham sabido, sobre o que sentiam a respeito da violação de direitos de crianças em ambientes conhecidos. É importante pensar nos critérios que o/a adulto/a elege para vetar ou não um tema, bem como a idade da criança que se considera ideal para discutir determinado tema na escola. Sem saber se a criança necessita desse espaço acolhedor de discussão, de roda de conversa para falar e ser ouvida sobre muitas questões, dentre elas a violência ou qualquer outro tema que a angustie.

O que parece existir na fala da professora, e no pensamento de muitas outras pessoas adultas, é uma infantilização exacerbada e universal das crianças, que as toma por uma massa de iguais, passando a ideia de uma infância única, muitas vezes romantizada, idealizada, mas que, de fato, essa infância não existe. Estar com a criança real, encontrar-se com ela, é o grande desafio da escola. É com essa criança, um ser social que interage na vida e com a vida, que tem muito a nos dizer, é com essas 
crianças, sobretudo as maiores, que participam de nossos projetos, no caso as de terceiro ao quinto ano do Ensino Fundamental, às quais possibilitamos espaço para pensar a partir de filmes e demais artefatos culturais, sobre temas que podem ser considerados 'feios e/ou insuportáveis', apesar de elas estarem imersas em imagens, sons e audiovisuais de fato inundados de violência, preconceito, segregação, bullying, sexismo, homofobia, machismo, violência contra crianças, contra a mulher e demais violações de direitos humanos, sem nenhum diálogo e discussão sobre essa avalanche de imagens e sons. Defendo, igualmente, que esses temas e os filmes com as temáticas em pauta possam e devam ser alvo de discussão na escola, nas instituições educativas, nos centros de educação infantil, sem moralismos, mas calcados nos direitos humanos. Defendo que tais discussões e diálogos ocorram com frequência e não sazonal, apesar de se saber que tal prática não é tão comum.

Penso nos pressupostos de diálogos, discussões e construção de pensamento com/para o cinema com as crianças. Há uma visão muito romantizada do que se considera infância, razão pela qual se impede que elas socialmente se confrontem com temáticas que fazem parte da vida de muitas delas. O mesmo se aplica à visão adultocêntrica da produção de filmes. As crianças, na maioria das vezes, são alijadas desse processo, embora sejam consumidoras vorazes desses produtos, sobretudo os de animação, sem um diálogo ou sem sua participação efetiva no processo de pré-produção, produção e pós-produção dos filmes.

Crianças e demais espectadoras/es não são sujeitos passivos diante do cinema e dos filmes. BERNARDET (2012) afirma que "no ato de ver e assimilar um filme, o público o transforma e interpreta, em função de suas vivências, inquietações, aspirações, etc" (BERNARDET, 2012, p. 84). Rosália Duarte também analisa essa questão dizendo que "[...] o olhar do espectador nunca é neutro, nem vazio de significados. Ao contrário, esse olhar é permanentemente informado e dirigido pelas práticas, valores e normas da cultura na qual ele está imerso" (DUARTE, 2002, p. 67). As crianças não são meros receptáculos passivos diante dos filmes e de outros audiovisuais; são seres ativos, e são a esses seres sociais que me refiro quando penso que podem interagir com o cinema para pensar com ele.

Os filmes que produzimos foram todos transversalizados com a temática dos direitos humanos. Cito dois cujos temas estão muito ligados a essa área: João e Maria, dos contos à realidade e Direitos das crianças: uma aventura intergaláctica. Inscritos em determinado festival de cinema para o público infantil no Brasil, não foram selecionados. No parecer de recusa, constava que os filmes eram muito bons, mas que o festival era 
infantil e a temática deles deveria ser direcionada a um público infantil, ou seja, os filmes não se destinavam a esse público.

Fiquei estupefata e, por muito tempo, pensativa sobre esse parecer, até mesmo porque os dois filmes haviam sido produzidos por crianças. As temáticas envolviam violência contra crianças. Um dos filmes, talvez fosse mais direcionado a crianças maiores (acima de 9 ou 10 anos), por se supor a necessidade de mais recursos cognitivos para o seu entendimento. Entretanto, ambos foram feitos por crianças. $O$ processo seguiu os seguintes passos nessa prática: submetemos a temática à turma de alunos/as e todo o processo foi realizado por e com elas/eles a partir de suas ideias e propostas.

Os roteiros foram escritos coletivamente e discutidos a partir do que as crianças viviam e sentiam sobre o problema. O primeiro filme é uma adaptação do conto João e Maria, no qual vemos muitas violações de direitos humanos, como abandono, violência física e psicológica. O outro, sobre a história de crianças terráqueas e extraterrestres, propôs discutir a situação de crianças no Brasil para evidenciar as que têm direitos garantidos e as que não.

O que podemos pensar do 'parecer' do festival, ao se pronunciar que tais filmes não seriam para crianças? Ou da opinião da professora de que esses temas não são possíveis de discussão com crianças de 10 a 12 anos? O que se pensa sobre a infância? Que infância se está construindo na cabeça das pessoas adultas? Há uma massificação e universalização das crianças? Pensa-se que as crianças não são seres sociais e culturais? Que não lidam e convivem com imagens e cenas de violência? E que muitas delas são as próprias vítimas das violências?

Que ideia romantizada da infância ainda paira nas concepções de educadores/as? Todas as crianças estão cuidadas e protegidas por suas famílias? Que tipo de famílias são idealizadas? E as crianças que sofrem violência de suas famílias? Famílias em que pai e mãe podem ser seus algozes? Será que as crianças não podem aprender a se cuidar e com isso se tornaram também sujeitos de vidas e tentar pedir ajuda em situação de violência? Os filmes não podem se tornar esses artefatos pedagógicos para ensinar as crianças a se cuidarem e pensarem sobre temáticas 'incômodas'? Não podem os filmes trazer temáticas para fazer pensar sobre temas que muitas crianças vivem? Não pode o cinema, como arte, trazer o incômodo para provocar o pensamento e novas formas de pensar?

São muitas questões a serem respondidas, mas não pretendo respondê-las neste texto. Deixo-as como reflexão e também como proposta para se pensar sobre as visões 
do público adulto a respeito das escolas, representadas pela professora que achava que essas temáticas não deveriam ser discutidas pelas crianças e/ou com elas, ou pelos/as pareceristas do festival que diziam que os filmes não eram para o público infantil. Entendo que essas temáticas são complexas para serem pensadas; provocam incômodo, estranhamentos... a arte tem esse intuito. No decorrer de nossas experiências também percebemos que, ao produzir filmes sobre esses temas, enfrentamos a possibilidade de produzir subjetividades nas crianças do terceiro ao quinto ano do Ensino Fundamental com as quais trabalhamos, além de nas crianças que podem ou poderão vir a assistir aos nossos filmes. A discussão dos direitos humanos promove a percepção de sujeitos de direito. Isso nos instiga a pensar sobre o segundo conceito-tema deste artigo, que são os direitos humanos.

Conceituar direitos humanos não é tarefa das mais fáceis. A Organização das Nações Unidas (ONU) adota o conceito mais amplo: "Direitos humanos são direitos inerentes a todos os seres humanos, independentemente de raça, sexo, nacionalidade, etnia, idioma, religião ou qualquer outra condição" (ONU, 2019). Talvez uma das dificuldades em sua conceituação se refira a sua intermitente violação, que é sistemática e ocorre em níveis mundiais. É comum vermos direitos humanos sendo violados a toda hora nos noticiários com atos que ferem profundamente a humanidade e a dignidade das pessoas.

A dignidade, outro conceito também bastante abstrato, constitui elemento fundamental dos direitos humanos. Se nos perguntarmos sobre a dignidade da vivência de um ser humano, diríamos que está intrinsecamente ligada à concretização de seu direito, não menos que outros direitos, como os de moradia, saúde, alimentação etc. A condição de dignidade só se efetiva na medida em que o direito é concretizado.

Benevides (2007) apresenta alguns dos princípios fundamentais dos direitos humanos, importantes, em sua opinião, para seu entendimento. Os direitos humanos se aplicam a todos os seres humanos, independentemente de onde quer que estejam vivendo. São históricos, portanto, produzidos historicamente e não 'dados' por alguém, instituição ou Estado. Foram conquistados por grupos e demais pessoas em níveis locais e internacionais. Os direitos não podem ser revogados e são indivisíveis, ou seja, não podem ser anulados, nem se pode escolher um em detrimento de outro, o que quer dizer que, como ser humano, necessito de direitos fundamentais para viver a minha dignidade, e por isso eles não podem sofrer uma seleção, com a escolha de um em detrimento de outro. 
O conceito de direitos humanos é trabalhado com as crianças em especial nos projetos em que se dá destaque a esse tema. Em todas as turmas, as crianças, em um primeiro momento, titubeiam em dizer se têm ou não direitos. Elas, na maioria das vezes, fazem uma lista de deveres, mas direitos, nem sempre sabem muito bem se os têm. Um dos direitos que acaba sendo controverso é o de 'estudar' que seria o da 'educação'. Ele é visto por muitas como um dever e não como um direito fundamental do ser humano. Aqui é necessário discutir para fazer ver que a educação escolar é um direito fundamental e que as crianças podem exigir uma escola mais democrática, mais acolhedora, mais receptiva para as pessoas. A educação é um direito humano reconhecido no artigo 26 da Declaração Universal dos Direitos Humanos de 1948. No Brasil, é um direito garantido pela Constituição Federal de 1988, no artigo 205, que diz: "A educação, direito de todos e dever do Estado e da família, será promovida e incentivada com a colaboração da sociedade, visando ao pleno desenvolvimento da pessoa, seu preparo para o exercício da cidadania e sua qualificação para o trabalho". Esse direito foi amplamente discutido com as crianças para encontrar uma diferenciação entre direito e dever.

O direito de brincar é amplamente discutido com as crianças. Sua violação também. Houve grupos que debateram muito sobre o trabalho infantil como uma violação dos direitos da criança, especialmente o trabalho doméstico das meninas. A violência contra crianças também foi amplamente citada nos projetos. Em alguns deles, tivemos que intervir, fazendo reuniões com a professora responsável pela turma, com a direção, havendo momentos em que tivemos que acionar a rede de proteção à criança para a efetivação de denúncia de violação de direitos.

A turma de 2018, solicitada a listar, por ordem, a violência contra a criança que mais Ihe chamava a atenção, o fez nessa ordem: física, sexual, psicológica, negligência/abandono, trabalho infantil e fatal. Após o grupo falar sobre os tipos de violência que mais lhe chamavam a atenção, levamos dados dos relatórios do Disque $100^{6}$ - Disque direitos humanos -, para apresentar dados de denúncias nacionais e estaduais de violação de direitos com o público de crianças e adolescentes. Debatemos os dados com os conhecimentos e sentimentos que isso posteriormente lhes provocava. Aprofundamos conhecimentos sobre direitos, algumas leis importantes e documentos

\footnotetext{
${ }^{6}$ O Disque 100 funciona, 24 horas por dia, diariamente, incluindo sábados, domingos e feriados. As ligações podem ser feitas de todo o Brasil por meio de discagem gratuita, de qualquer terminal telefônico, fixo ou móvel (celular), bastando discar 100. O serviço pode ser considerado como "pronto socorro" dos direitos humanos, pois atende também a graves situações de violação que acabaram de ocorrer ou que ainda estão em curso, acionando os órgãos competentes, possibilitando o flagrante. O Disque 100 recebe, analisa e encaminha denúncias de violações de direitos humanos de crianças e adolescentes e de outros grupos vulneráveis. Disponível em: <https://www.gov.br/mdh/pt-br/acesso-a-informacao/disque-100-1>. Acesso em: 28 abr. 2020.
}

Revista Digital do LAV - Santa Maria - vol. 13, n. 2, p. 291 - 311 - mai./ago. 2020 ISSN $1983-7348$ http://dx.doi.org/10.5902/1983734844248 
nacionais e internacionais, dentre eles a Declaração Universal dos Direitos das Crianças (1959). Nesse processo, as crianças começaram a se ver como cidadãs, entendimento que crescia à medida que tomavam conhecimento das leis, que se reconheciam como sujeitos de direitos e sabiam que podiam passar a exigi-los. Depois disso é que passamos a produzir os roteiros e a brincar de fazer cinema com temáticas (im)pertinentes.

O filme Cantando os direitos humanos foi um deles e seguiu exatamente o roteiro acima. O roteiro foi feito a partir de um rap de uma das alunas do grupo do $5^{\circ}$ ano do Ensino Fundamental. Ela esboçou uma ideia e, a partir daí, fomos - o grupo de crianças e adolescentes da turma mais a equipe - construindo juntos o roteiro. O filme conta a história de um show de competição musical de duas duplas de MCs que cantam raps. Ao cantarem, vemos os clips das músicas. Há uma exaltação dos direitos humanos das crianças e de uma menina que exige a garantia dos seus, questionando, inclusive, as investidas sexuais dos homens mais velhos.

Antes da produção, como já expliquei, estabelecemos como primeira etapa conhecer o que as crianças já sabiam sobre os temas, seguida pela discussão e pela construção do aprendizado para a produção do filme. É nesse processo - ao longo do trabalho - que percebemos quão pouco as crianças conhecem de seus próprios direitos. Em alguns casos, elas se sentem assustadas ao saber que possuem direitos, além de não saberem bem o que seja isso.

Para saber sobre seus direitos, perguntamos sobre uma instituição importante que deveria ser de conhecimento das crianças - o Conselho Tutelar. Na turma de 2018, do $5^{\circ}$ ano, composta por 22 crianças (10 meninas e 12 meninos), somente três delas sabiam que o conselho era 'um lugar que ajuda/cuida e defende as crianças'. Quatro crianças disseram que o conselho era 'algo para crianças desobedientes'; três que era 'algo ou alguém que pega criança ou adolescente'; duas disseram que é um lugar que 'cobra presença na escola'; três disseram não saber o que seria ou para que serviria o conselho; sete delas disseram respostas diversas, dentre elas: 'local que pune a criança', 'polícia de criança' e 'para pegar a criança e colocar para trabalhar'.

O Conselho Tutelar, conforme o Estatuto da Criança do/a Adolescente (outro documento muito importante e quase totalmente desconhecido de grande parte das crianças que participaram de nossas pesquisas), afirma, no artigo 131, tratar-se de um órgão permanente e autônomo, não jurisdicional, encarregado pela sociedade de zelar pelo cumprimento dos direitos da criança e do/a adolescente. Ele faz parte da rede de proteção dos direitos da criança, assim como a escola. Suas atribuições são atender e zelar pelos direitos de crianças e adolescentes, requisitar serviços públicos, encaminhar 
notificações de violação de direitos, enfim, tem como propósitos velar pelos direitos da criança. As crianças dos nossos projetos, em nenhum dos anos, sabiam de suas atribuições em prol de seus próprios direitos; ao contrário, viam o conselho como instituição com o poder de puni-las, de ser 'polícia das crianças', de fazê-las trabalhar. O mesmo se aplica ao desconhecimento do Disque 100, que se trata de um serviço do Governo Federal para receber denúncias de casos de violação de direitos de crianças e outros grupos vulnerabilizados. Das 22 crianças que responderam ao questionário, quatro já tinham ouvido falar sobre o Disque 100. Para elas, o número era para ajudar e proteger as crianças; seis crianças disseram que era um número para denúncia, mas não sabiam para que público específico; duas, que era um local para ligar sobre violência contra a mulher; nove não sabiam e uma criança não respondeu. Sobre a informação do Disque 100, como se viu, poucas sabiam que se trata de um serviço disponível para denúncia de casos de violência contra as crianças. Algo que as vulnerabiliza cada vez mais, porque ignoram como e onde recorrer em situações de violação de seus direitos.

A esse mesmo grupo foi perguntado se, caso sofresse algum tipo de violência em casa pela própria família, a quem pediria ajuda? As crianças responderam, nessa ordem: avó; tio/tia; avô; vizinho/a e professor/a; mãe; pai e outros (padrinho, diretor da escola, irmão, polícia, algum/a profissional da escola). Vemos, aqui, a figura da avó como a pessoa de referência caso ocorra alguma violência contra a criança e só em quarto lugar o/a vizinho/a e o/a professor/a. O/a docente é um profissional importantíssimo nesse processo de quebrar a teia e a corrente da violência contra a criança e o/a agressor, com um olhar sensível, acolhedor e atento para fazer as denúncias e/ou notificações das violências sofridas pela criança, até mesmo porque é, segundo o Estatuto da Criança e do Adolescente (1990), uma de suas atribuições, como consta do artigo 245: "Comunicar à autoridade competente os casos de que tenha conhecimento, envolvendo suspeita ou confirmação de maus-tratos contra criança ou adolescente".

No filme Eu protejo meu corpo, que realizamos com uma turma do 30 ano do ensino fundamental, as crianças não sabiam a quem pedir ajuda numa situação de violência. Como já referido, poucas conheciam o Disque 100 e o Conselho Tutelar. Passamos a discutir sobre esses temas por meio do livro Do meu corpo eu cuido e protejo, de minha autoria (2016). O corpo passou a ser um assunto de referência, e nele estudamos os nomes de todas as suas partes, inclusive dos órgãos genitais. Muitas crianças ficaram horrorizadas por pronunciarmos abertamente os nomes científicos dos órgãos genitais. Aos poucos, porém, isso passou a ser comumente aceito pelo grupo. Passamos a falar sobre onde as pessoas podem ou não tocar seus corpos; da questão do segredo; das pessoas de referência dentro e fora da família; de como elas poderiam se 
cuidar e se proteger em situação de violência; de como e onde buscar ajuda em situação de violação de direitos. Esta é uma questão importante no projeto: trabalhar a possibilidade de a criança se proteger não significa que as pessoas adultas não devam fazer e realizar o seu papel primordial de cuidar da criança como está preconizado no Estatuto da Criança e do Adolescente, no artigo quarto e em outros, em que se declara: "É dever da família, da comunidade, da sociedade em geral e do poder público assegurar, com absoluta prioridade, a efetivação dos direitos referentes à vida, à saúde, à alimentação, à educação, ao esporte, ao lazer, à profissionalização, à cultura, à dignidade, ao respeito, à liberdade e à convivência familiar e comunitária" de crianças e adolescentes. Mesmo ciente desse dever de todas as pessoas da sociedade, vejo que a própria criança tem o direito de dizer não quando algo não the agrada; o direito a ter direito ao seu próprio corpo; direito a ser respeitada com toda a dignidade que lhe é inerente.

Os principais direitos humanos das crianças estão presentes em todos os filmes que produzimos, bem como adicionamos o Disque 100 como um possível aliado das crianças para elas se protegerem e utilizarem em caso de violação de seus direitos. No filme Jéssica e Júnior no mundo das cores, discutimos sobre o direito de meninas e meninos viverem livres das normatizações das idealizações de gênero. O direito de brincar e de ser dignamente livres está muito presente nas personagens e no roteiro do filme. Em Ser criança em Campo Grande: um documentário animado, também destacamos o direito de brincar e imaginar. Neste filme, também focalizamos o direito à cidadania e à vida na cidade, a partir do olhar da criança. Em A Princesa Pantaneira, há uma experimentação do direito de ser quem se quer ser, de ser menina e de ser menino, de muitas formas, sem ser repreendido por isso, de brincar sem ser repreendido pelas normas de gênero, de ter direito a conhecer e a exaltar suas identidades culturais e regionais. Em Queityléia em perigos reais, enfatizamos vários tipos de violência, dentre elas a exposição de crianças na Internet e o direito de serem protegidas e cuidadas neste ambiente por elas próprias e pelas pessoas adultas. Nesse filme, começamos com a possibilidade de a própria criança aprender a se cuidar e a se proteger em situações de perigo e de vulnerabilidade. Em Direitos das crianças: uma aventura intergaláctica, destacamos diversos direitos, sobre os quais não se fala tanto, como direitos à alimentação, à educação, à amizade entre as crianças, a brincar e, especialmente, o direito da criança de ter alguma decisão política, de ser ouvida em decisões que envolvem questões que Ihes dizem respeito na vida pública. Em João e Maria: dos contos à realidade, as crianças também são protagonistas; aliás, esta é uma característica de todos os nossos filmes. Nesse, em especial, elas corajosamente enfrentam o abandono, a 
rejeição e o comércio de seus corpos para depois conseguirem se salvar. A criança, como sujeito de direito e como cidadã, é foco do roteiro desse filme, além de trazer o Disque 100 como um aliado na condição de efetivação dos seus direitos. Em Cantando os direitos das crianças, como o próprio título diz, os direitos humanos são cantados e entoados em voz alta pelas crianças, que exigem que seus direitos sejam respeitados, como o direito a se constituir uma família de muitos jeitos, direito a ter as condições básicas de dignidade, direito de ser menina e mulher e de ser respeitada pelos homens. Em Eu protejo o meu corpo, falamos do direito a ter um corpo e a de protegê-lo. Os direitos da criança de ser ouvida em situação de violência e de ser cuidada e protegida são amplamente tratados neste filme. Embora a criança precise se cuidar e proteger, insistimos na obrigação do/adulto/a de fazê-lo por força da legislação. Em Mariquinha no mundo da imaginação, os direitos de brincar e de imaginar são os mais marcantes; este é o que se inspira nas poesias do Manoel de Barros. Os três últimos filmes - Princesa Pantaneira YouTuber, Princesa Pantaneira responde: cinema e Brincar de fazer cinema com crianças - incluem, entre os direitos fundamentais, o de imaginar, o de brincar, o de estar próximo à natureza e de brincar de fazer cinema. O direito de brincar é um dos direitos fundamentais da criança e o de brincar de fazer cinema na escola é uma das possibilidades de pensar em si, no mundo, nas outras pessoas.

\section{Considerações finais}

'Um cinema que 'educa' é aquele que (nos) faz pensar - e que (nos) faz pensar não somente sobre o cinema em si mesmo, mas, igualmente, sobre 'as mais variadas experiências e questões que ele coloca em foco"' (XAVIER, Ismail, 2008, p. 14).

Pretendi, ao longo deste texto, relatar parte da trajetória dos meus encontros com o cinema, com o cinema de animação, com as crianças na escola como produtoras de filmes de animação sobre direitos humanos.

Como se viu, Bergala (2008) assegura que não se ensina a arte, mas se 'encontra' com ela. Encontrei-me com o cinema quando fui a um festival e nunca mais desisti de ver realizado meu desejo de produzir filmes. Vejo nos filmes possibilidades de produzir e provocar pensamentos, por isso, tanto os que produzimos com as crianças, como outros e demais artefatos culturais, não devem sofrer censura com pressupostos moralistas do tipo que isso não serve para criança, que não é da faixa etária dela, ou que o assunto seria tão hermético que ela não entenderia. No cinema como arte, na medida em que a escola propicia esse encontro do cinema com a criança, poderá ocorrer essa possibilidade de diálogo e de comunhão. O papel da pessoa adulta é fundamental no processo de 
propiciar momentos de fruição ou de fazer filmes com as crianças, para não levar a elas somente um tipo de filme, de conteúdo ou de linguagem. Seu papel é o de ampliar o repertório temático, de possibilitar múltiplas linguagens e temáticas, potencializando a arte que provoca, inquieta, questiona, problematiza.

O processo de produção dos filmes com as crianças sempre foi rico e acompanhado por encontros desafiadores com temáticas consideradas por muitos como (im)pertinentes. Concordo que são temas difíceis e complexos, nem sempre belos, que beiram, às vezes, o (in)suportável. Posso aqui afirmar que, no caso específico, há vários anos, eu e equipe temos trabalhado de forma muito cuidadosa, atenta, respeitosa, zelosa, ética e estética, partindo de frases narradas, de histórias contadas pelas crianças, de notícias por elas ouvidas nas redes sociais. Trazemos aspectos da realidade, mas também utilizamos estratégias da imaginação para aguçar a criatividade e o trabalho cooperativo que uma produção fílmica exige. O lúdico e a brincadeira estão presentes em todo o processo, até porque propiciar momentos para o pensamento pode ser mágico e prazeroso. Também vejo no filme tanto a possibilidade de o ver e saborear o como fazêlo, assim como uma das formas poderosas de produção de pensamento. Os filmes que levamos para serem exibidos no projeto e os que produzimos têm esse propósito: o de produzir formas de pensar e novas formas de pensar. É sobre essa possibilidade que me inspira Ismail Xavier quando diz que um cinema que educa é o que nos faz pensar, não só sobre o filme em si, mas sobre tudo o que dele pode derivar ou multiplicar; possibilidade de pensarmos em nós e de nos tornarmos seres melhores.

O que observamos, ao longo das experiências com as crianças, é que seria fundamental propiciar às demais crianças momentos para a produção de pensamentos e de encontros com a arte nas instituições educativas. Os nossos filmes podem ser os articuladores desse processo, da mesma forma que inúmeros outros filmes e demais artefatos, como livros, artes plásticas, gravuras, performances... Precisamos encontrar o espaço do cinema como arte como um momento de se encontrar com as crianças nas escolas. Precisamos encontrar espaços para o diálogo com as crianças para as podermos escutar, momentos para um diálogo franco, para promover rodas de conversas como fazemos na Educação Infantil e que depois se tornam esquecidas nos anos iniciais do Ensino Fundamental. Precisamos nos encontrar com as crianças e fazê-las se encontrar com as artes como instrumento para expressar seus sentimentos, pensamentos, anseios, desejos, alegrias, tristezas, projetos de vida, vontades de vida.

\section{Referências}

Revista Digital do LAV - Santa Maria - vol. 13, n. 2, p. 291 - 311 - mai./ago. 2020 ISSN 1983 - 7348 http://dx.doi.org/10.5902/1983734844248 
BENEVIDES, M. V. Direitos humanos: desafio para o século XXI. In: SILVEIRA, R. M. G. et al. Educação em direitos humanos: fundamentos teórico-metodológicos. João Pessoa: Editora Universitária, 2007.

BERGALA, A. A hipótese-cinema. Rio de Janeiro: Booklink; CINEAD-LISE-FE/UFRJ, 2008.

BERNARDET, J.-C. O que é cinema. 21. ed. São Paulo: Brasiliense, 2012.

BRASIL. Lei $\mathbf{n}^{\circ} \mathbf{1 3 . 0 0 6}$ de 2014, que alterou o texto da Lei de Diretrizes e Bases da Educação Nacional - Lei nº 9.394/96.

BRASIL. Estatuto da Criança e do Adolescente (ECA), instituído pela Lei no 8.069, de 13 de julho de 1990. Disponível em: <portal.mj.gov.br>. Acesso em: 18 out. 2019.

DUARTE, R. Cinema e educação. Belo Horizonte: Autêntica, 2002.

FRESQUET, A.; MIGLIORIN, C. Da obrigatoriedade do cinema na escola, notas para uma reflexão sobre a Lei 13.006/14. In: FRESQUET, A. (Org.). Cinema e educação: a lei 13.006, reflexões, perspectivas e propostas. Universo Produções, 2015.

GALLO, S. Metodologia de ensino de filosofia: Uma didática para o ensino médio. Campinas, SP: Papirus, 2012.

ONU. Declaração Universal dos Direitos da Criança, 1959.

ONU. Declaração Universal dos Direitos Humanos, 1948.

ONU/BRASIL. 0 que são direitos humanos. Disponível em: <https://nacoesunidas.org/direitoshumanos/>. Acesso em: 18 out. 2019.

XAVIER FILHA, C. (Org.). Kit de Materiais Educativos de Educação para a Sexualidade, para a Equidade de Gênero e para a Diversidade Sexual. Campo Grande, MS: Editora da UFMS, 2009a.

XAVIER FILHA, C. A menina e o menino que brincavam de ser... Campo Grande: EdUFMS, 2009b.

XAVIER, I. Um cinema que "educa" é um cinema que (nos) faz pensar. In: Revista Educação e Realidade, v. 33, n. 1, jan./jun. 2008. p. 13-20.

' Doutora em educação pela USP, Pós-doutora em Educação pela Unicamp. Professora da Universidade Federal do Mato Grosso do Sul.

Como citar esse artigo:

FILHA, Constantina Xavier. Encontros com o cinema de animação e com crianças na produção de filmes sobre direitos humanos. Revista Digital do LAV, Santa Maria: UFSM, v. 13, n. 2, p. 291-311, mai./ago. 2020. 